\title{
Uçak Kanadının Entegre Güçlendirilmiş Panel Yapıları Kullanılarak Yapısal Tasarımı*
}

\author{
Kazım Tekkanat ${ }^{1 *}$, Ömer Keleş ${ }^{2}$ \\ ${ }^{1}$ Gazi Üniversitesi, Fen Bilimleri Enstitüsü, Makina Mühendisliği Bölümü, Ankara, Türkiye (ORCID: 0000-0001-6346-1611) \\ ${ }^{2}$ Gazi Üniversitesi, Fen Bilimleri Enstitüsü, Makina Mühendisliği Bölümü, Ankara, Türkiye (ORCID: 0000-0002-3480-3456)
}

(Konferans Tarihi: 5-7 Mart 2020)

(DOI: 10.31590/ejosat.araconf9)

ATIF/REFERENCE: Tekkanat, K., \& Keleş, Ö. (2020). Uçak Kanadının Entegre Güçlendirilmiş Panel Yapıları Kullanılarak Yapısal Tasarımı. Avrupa Bilim ve Teknoloji Dergisi, (Özel Sayı), 64-71

$\ddot{O} \mathbf{z}$

Günümüzde artan teknoloji ile birlikte hava araçlarında kullanılan malzemeler ve üretim metotları da gelişmektedir. Uçakların üretildiği ilk yıllarda tahta kullanımından başlayan malzemelerin yerini günümüzde entegre yapılar, eklemeli imalat ile üretilen 3D parçalar ve kompozit malzemeler almıştır. Bu yeni nesil malzemeler sayesinde çok daha hafif ve dayanıklı uçaklar yapılabilmekte ve çok daha geniş bir tasarım özgürlüğüne sahip olunmaktadır. Bu çalışmada günümüz yeni nesil üretim teknolojilerinden biri olan entegre güçlendirilmiş panel metoduyla uçak kanat panel tasarımı yapılacaktır. Çalışmanın ana amacı farklı güçlendirme geometri ve panel yapılarının burkulma performanslarını karşılaştırmak ve aynı ağılıkta en fazla yük taşıma kapasitesine sahip paneli belirlemektir. Havacılık endüstrisi hava araçları yapılarında parça sayısını azaltma yönünde evirilmektedir. Burkulma performansının yanında montaj süresinin kısalması, montajda açılması gereken bağlayıcı sayısının düşmesiyle birlikte yapı üzerindeki pürüzlerin azalması ve potansiyel çatlak oluşumunun önüne geçilmesi, montaj için gerekli erişim ihtiyacının azalması gibi avantajları da entegre yapıların tercih edilme sebepleri arasındadır. Çalışmada dört farklı panel tasarımı yapılarak karşılaştırma yapılmıştır. Çalışma sonucunda elde edilen veriler, uçak yapılarında basma yüklemesine maruz kalan ve kritik yükleme koşulu burkulma olan panellerde, özellikle kanat üst kabukları, ağırlık, montaj ve maliyet efektif tasarımlara yön verebilecektir.

Anahtar Kelimeler: Entegre panel yapılar, Burkulma, Uçak kanadı, Uçak yapıları, Yapısal tasarım

\section{Structural Design of Aircraft Wing by Using Integrally Stiffened Panel}

\begin{abstract}
Materials and manufacturing methods that use in aerospace industry improve by recently technological developments. Wood was the material on first years of aircraft manufacturing but nowadays integrally structures, additive manufacturing and composite materials can be used. Through these new generation materials and manufacturing methods more light and strong aircraft structures can be designed and manufactured. In this work, by using integrally stiffened panel method that is one of the new generation manufacturing method aircraft wing panel was designed. The main purpose of this work is to investigate the effect of different stiffener geometry and panel structures in terms of buckling performance. Furthermore buckling performance, aerospace industry evolves in decreasing the number of part number. This method also helps decreasing manufacturing time, the number of fastener and fastener holes, potential crack start and access requirement for assembly process. In this work, four different panel geometry are designed and compared. More weight, assembly and cost effective design shall be done on panels which is under compressive loading especially wing upper panel by using the result of this work.
\end{abstract}

Keywords: Integrally panel structures, Buckling, Aircraft wing, Aircraft structures, Structural design

\footnotetext{
* Kazım Tekkanat: Gazi Üniversitesi, Fen Bilimleri Enstitüsü, Makina Mühendisliği Bölümü, Ankara, Türkiye, ORCID: 0000-0001-6346-1611, kazim.tekkanat@.gmail.com
}

** Bu makale International Conference on Access to Recent Advances in Engineering and Digitalization (ARACONF 2020) de sunulmuştur. 


\section{Giriş}

Entegre paneller yüksek dayanımları ve düşük ağırlık çözümleriyle hava aracı yapılarında çoğunlukla öne çıkmaktadır. Montajda gerekli parça ve bağlayıcı sayısını azaltma, montaj süresini kısaltma gibi yan faydalarının yanında basma yükleri altında burkulma performanslarında da iyileşme olmaktadır. Uçak kanatlarında, üzerlerine gelen kaldırma kuvvetinden kaynaklanan eğilme momenti üst kabukta basma, alt kabukta çekme yüklemesine sebep olmaktadır. Bu yüzden genellikle kanat üst kabuk panelleri için en kritik yükleme burkulma olmaktadır. Quinn ve arkadaşları yaptıkları çalışmalarında entegre güçlendirilmiş panel yapılarını araya yardımcı güçlendirici atarak ve atmayarak karşılaştırmış ve burkulma yükü için \%87.2, panel burkulması için \%17.7 artış gözlemlemişlerdir [1]. NASA'nın yapmış olduğu çalışmada sonradan birleştirme ile üretilen paneller entegre panel yöntemiyle tekrar tasarlanmış ve üretilmiştir. Çalışma kapsamında 78 parçalık bir kanat montajı ele alınmış ve 7 parçalık bir montaj haline getirilerek toplamda \%58'lik bir ağırlık avantajı sağlanmıştır [2]. Murphy ve arkadaşları benzer şekilde entegre güçlendirilmiş panellerin burkulma performanslarını karşılaştıran bir çalışma yapmış ve panele eklenen yardımcı güçlendirici elemanların burkulma performansını \%11.1 artırdığını tespit etmişlerdir [3]. Bu çalışmada farklı güçlendirici kesit alanları ve panel yapılarının burkulmaya karşı dayanım performansları karşılaştırılacaktır.

\section{Materyal ve Metot}

Çalışmada Al-7050 alaşımlı malzemeye sahip aynı ağırlıkta 4 farklı panel kullanılmıştır. Panel boyutları belirlenirken aynı ağırlıkta farklı geometrilerde paneller belirlenmeye çalışıldığ 1 için karşılaştırma yapılabilmesi için kabuk kalınlığı ve panel boyutları sabit tutulmuştur. Eklenen güçlendirici elemanlarının panel burkulma performansları üzerine etkisi incelendiğinden, güçlendirici boyutları her panelde Hata! Başvuru kaynağı bulunamadı. de gösterildiği şekilde farklıdır.

\subsection{Panel Boyutları}

Panel_A ve Panel_B ana güçlendirici geometrileri I kesit alanına sahip paneller olup, Panel_B de ekstra yardımcı güçlendiriciler bulunmaktadır. Panel_C ve Panel_D de ana güçlendirici geometrileri T kesit alanına sahip olur, Panel_D de ana güçlendiriciler arasında yardımcı güçlendirici elemanlar bulunmaktadır (Şekil 1).

Tablo 1. Panel Boyutlarl

\begin{tabular}{|l|l|l|l|l|}
\hline & Panel_A & Panel_B & Panel_C & Panel_D \\
\hline Boy (mm) & 800 & 800 & 800 & 800 \\
\hline Genişlik (mm) & 500 & 500 & 500 & 500 \\
\hline Kabuk Kalınlığ1 (mm) & 2,5 & 2,5 & 2,5 & 2,5 \\
\hline Ana Güçlendirici Kalınlığı (mm) & 4,4 & 3 & 3,2 & 2,2 \\
\hline Ana Güçlendirici Yükseklik (mm) & 28 & 28 & 28 & 28 \\
\hline Yardımc1 Güçlendirici Kalınlığ1 (mm) & - & 2 & - & 1,4 \\
\hline Ana Güçlendirici Kesit & $\mathrm{I}$ & $\mathrm{I}$ & $\mathrm{T}$ & $\mathrm{T}$ \\
\hline Ağırlık (g +/- 40 g ) & 4000 & 4000 & 4000 & 4000 \\
\hline
\end{tabular}

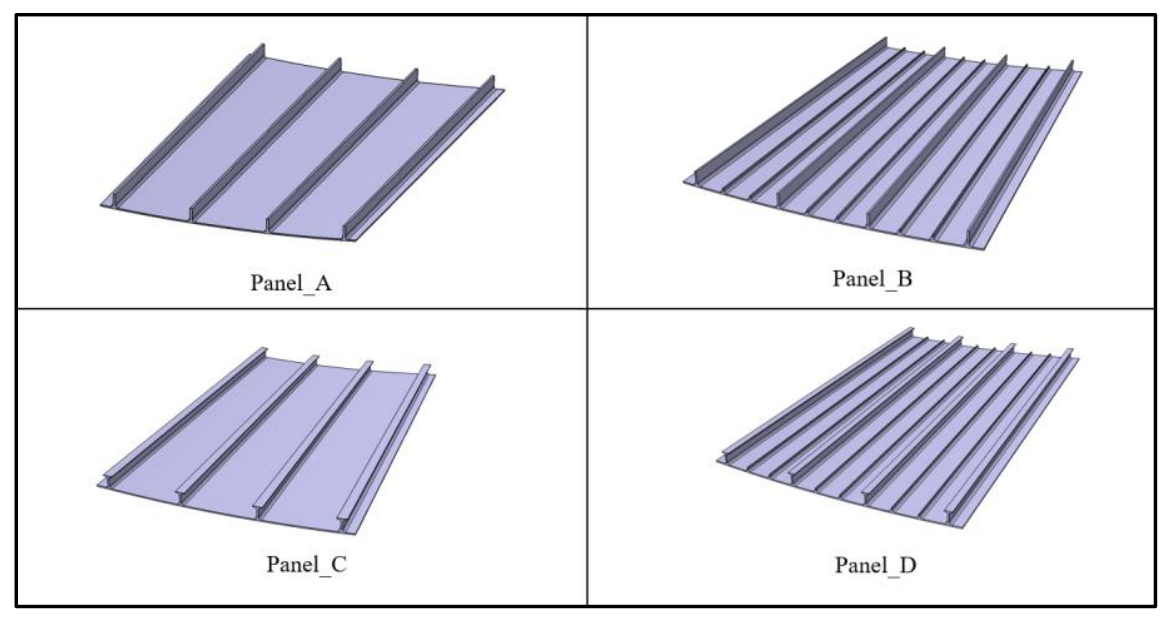

Şekil 1. Panel İzometrik Görünüşleri 
Tablo 2. Al 7050-T7451 Malzeme Özellikleri (A Basis) [6]

\begin{tabular}{|l|l|l|}
\hline \multicolumn{2}{|l|}{ Al 7050-T451 } \\
\hline Elastisite modülü & 71016 & $\mathrm{MPa}$ \\
\hline Poisson oran1 & 0,33 & - \\
\hline Ftu & 510,21 & $\mathrm{MPa}$ \\
\hline Fty & 441,26 & $\mathrm{MPa}$ \\
\hline e & 0,09 & - \\
\hline
\end{tabular}

\subsection{Sonlu Elemanlar Modeli Doğrulama}

Sonlu elemanlar modelini doğrulama yöntemi olarak literatürde test içeren bir makale kullanılacaktır. MSc.Nastran'da yapılan sonlu elemanlar analizi sonucu, makalede verilen test sonuçları karşılaştırılarak aradaki fark belirlenecektir. Test ve fem sonuçlarının birbirine yeterli seviyede yakın olduğu gösterilmeye çalışılarak, bundan sonraki paneller için sadece fem analizi yapılması yeterli olacaktır. Doğrulamada kullanılacak olan makale, literatür araştırması kısmında detaylıca anlatılan Quinn ve arkadaşlarının [1] makalesi olacaktır.

Şekil 2'de Quinn makalesindeki test numunesi_A gösterilmiştir. Test numunesi $50 \mathrm{~mm}$ kalınlığındaki aluminyum alaşım 2024T351 plakadan talaşlı imalat olarak işlenmiş̧ir.

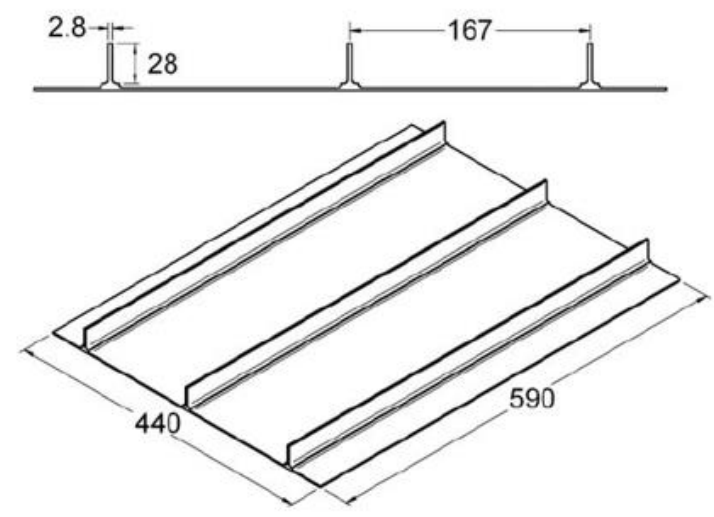

Şekil 2. Test numunesi A geometrik modeli [1]

Şekil 3’te gösterilen test numunesi A 5 mm'lik dört düğüm noktası içeren dörtgen CQUAD4 sonlu elemanlar ağı ile örülmüş̧ür. Ağ boyutu burkulma analizi sonuçlarını etkileyeceği için bir yarım burkulma dalgasında en az 10 eleman olmasına dikkat edilmiştir.

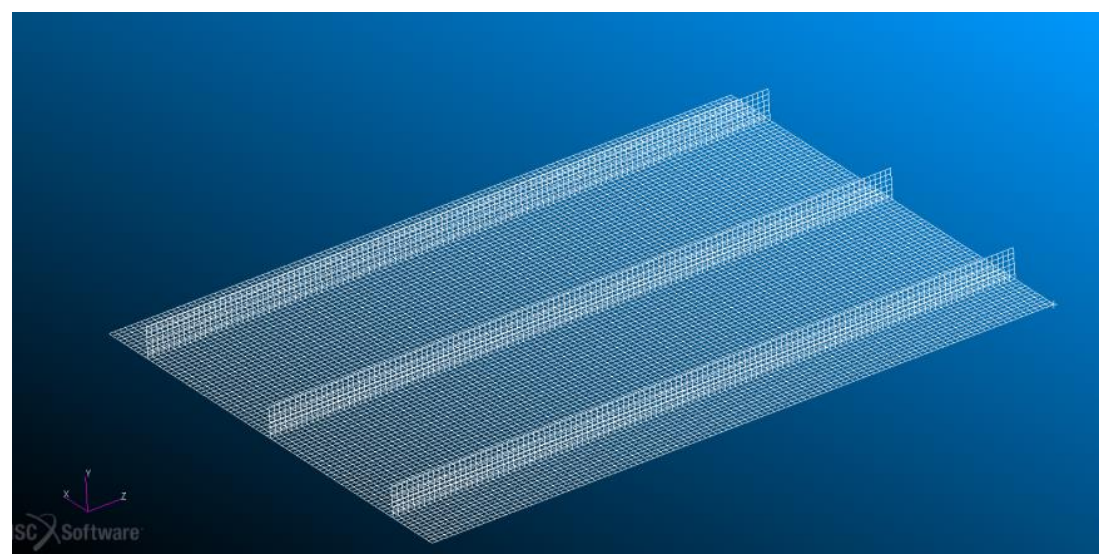

Şekil 3. Sonlu elemanlar ă̆ı örülmüş numune_A modeli

Kabuk ve web yapıları, kalınlıklarının yarısındaki iki boyutlu yüzeylerde idealize edilmiştir. Kabuk ve web arasında oluşan kabuk kalınlığının yarısı kadar olan mesafe ihmal edilmiştir. 


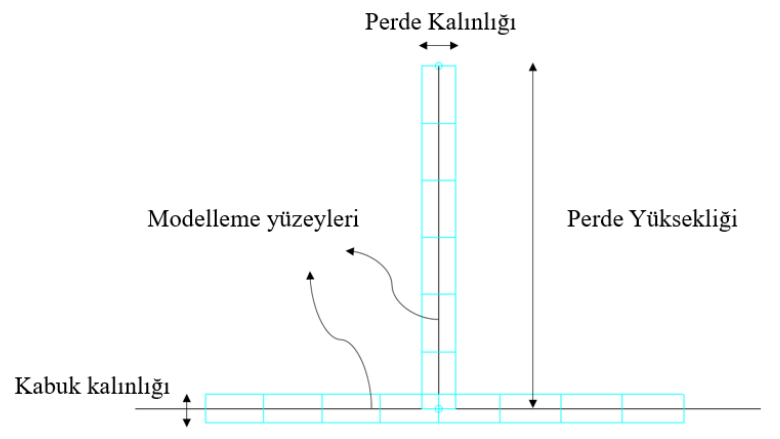

Şekil 4. Sonlu Elemanlar Modelinde Kullanılan Yüzeyler

MMPDS'den [6] alınan Al 2024-T351 malzeme özellikleri aşağıdaki tabloda listelemiştir. Metalik malzeme özellikleri MAT1 kartını kullanarak tanımlanmıştır. Panel kalınlıkları PSHELL kartı ile tanımlanmıştır.

Tablo 3. Al 2024-T351 Malzeme Özellikleri (A Basis) [6]

\begin{tabular}{|l|l|l|}
\hline Al 2024 -T351 & $\mathrm{MPa}$ \\
\hline Elastisite modülü & 73773 & - \\
\hline Poisson oran1 & 0,33 & $\mathrm{MPa}$ \\
\hline Ftu & 413,68 & $\mathrm{MPa}$ \\
\hline Fty & 289,57 & - \\
\hline e & 0,04 & - \\
\hline
\end{tabular}

Panele test yüklemesini modellemek için z yönündeki kenarlarından sınır koşulları uygulanmıştır. Bir kenarı x,y ve z eksenlerinde tamamıla sınırlandırılmış olup, diğer kenarı $\mathrm{x}$ ve y de sınırlandırılarak $\mathrm{z}$ yönünde $1 \mathrm{~mm}$ basma yönünde yer değiştirme tanımlanmıştır.

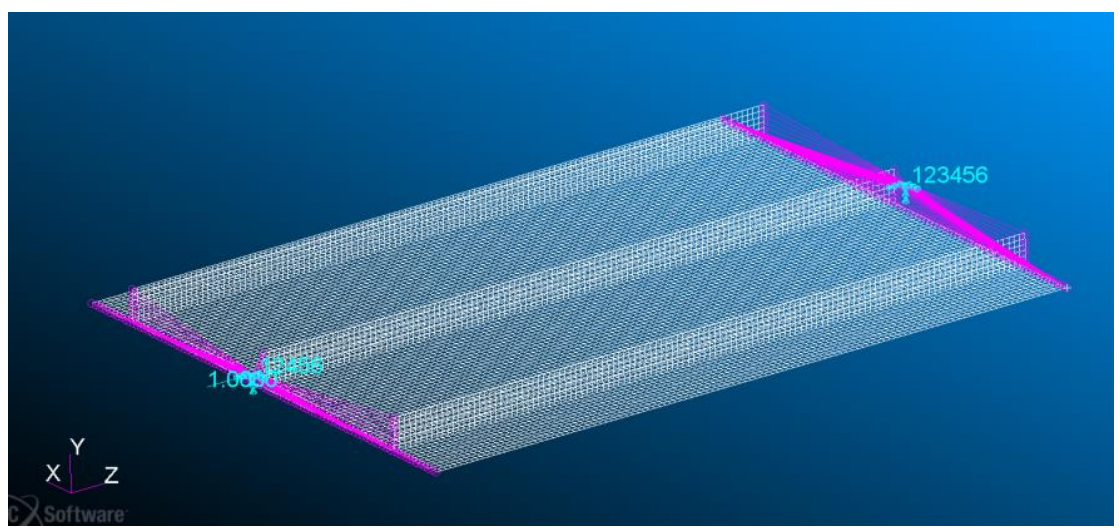

Şekil 5. Sonlu Elemanlar Modelindeki Sinır Koşulları

İlk burkulma yükü ve modunu elde etmek için Nastran SOL105 kullanarak doğrusal özdeğer analizi (Linear eigenvalue analysis) koşturulmuş̧ur. Analiz sonucu elde edilen ilk burkulma modu Şekil 6'da gösterilmiş̧tir.

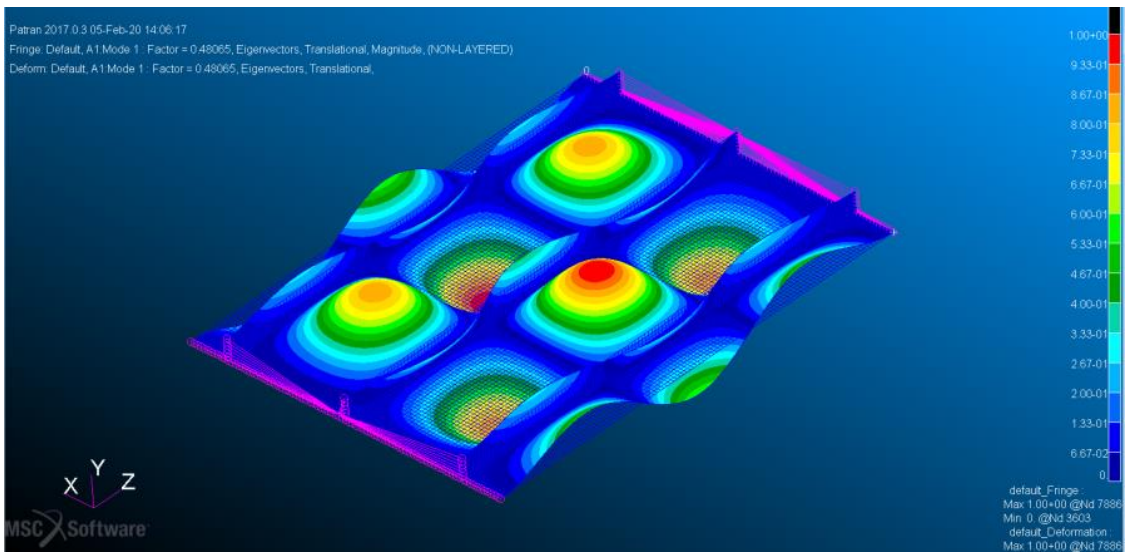

Şekil 6. Illk burkulma modu - FEM sonucu 
Yapılan burkulma analizi sonucu $\lambda=0,485$ olarak bulunmuştur. Bu değer panelin ilk burkulma modunun toplam yüklemenin ne kadarında gerçekleştiğini gösteren faktör değeridir. Statik analiz sonucunda tepki kuvveti $156000 \mathrm{~N}$ olarak bulunmuş olup, ilk burkulma modunun görüleceği kuvvet aşağıdaki gibi hesaplanmıştır.

$$
F_{T} * \lambda=156000 * 0,485=75,7 k N
$$

$F_{T}:$ Tepki kuvveti

$\lambda:$ Özdeğer (Eigenvalue)

olarak bulunur. Referans alınan makaledeki Quinn [1] in yaptığı test sonucu panel 74,5 kN de ilk burkulma moduna girmektedir. Yapilan patran analizi sonucu test sonucuna;

$$
\% \text { Hata }=\frac{75,7-74,5}{74,5} * 100=\% 1,6
$$

oranında yaklaşmıştır. Bu göz ardı edilebilir hata oranı fem de kullandığımız yöntemin doğru olduğunu göstermekte ve bundan sonra panelleri aynı yöntemle sonlu elemanlar yöntemi kullanarak analiz edebileceğimizi göstermektedir.

Analizin ikinci kısmında burkulma sonrası incelenip yapının taşıyabileceği maksimum yük belirlenecektir. Burkulma sonrası kısımda yapıda doğrusal olmayan geometrik ve malzeme davranışlar oluşacaktır. Panel tamamen çökme aşamasına gelene kadar önce elastik sonra plastik bölgede yüklenecek ve sonunda tamamen çökecektir. Bu sebeple öncelikle doğrusal olmayan bölgedeki malzeme özellikleri tanımlanmalıdır. Doğrusal olmayan malzeme özellikleri Ramberg-Osgood eğrisini[8] kullanarak modellenmiş ve gerilimgerinim eğrisi Msc. Patran'da MAT1 kartı ile tanımlanmıştır. Ramberg-Osgood metalik malzemeler için gerçek mühendislik gerilim gerinim eğrisini tanımlayan matematiksel bir yaklaşımdır. Yapı üzerindeki geometrik lineer olmayan davranışı modellemek adına ilk burkulma modunu oluşturacak şekilde 0.02 N'luk kuvvetler ile yapıda panelin düzlem dışı yönünde bükülme oluşturmaya çalışılmıştır.

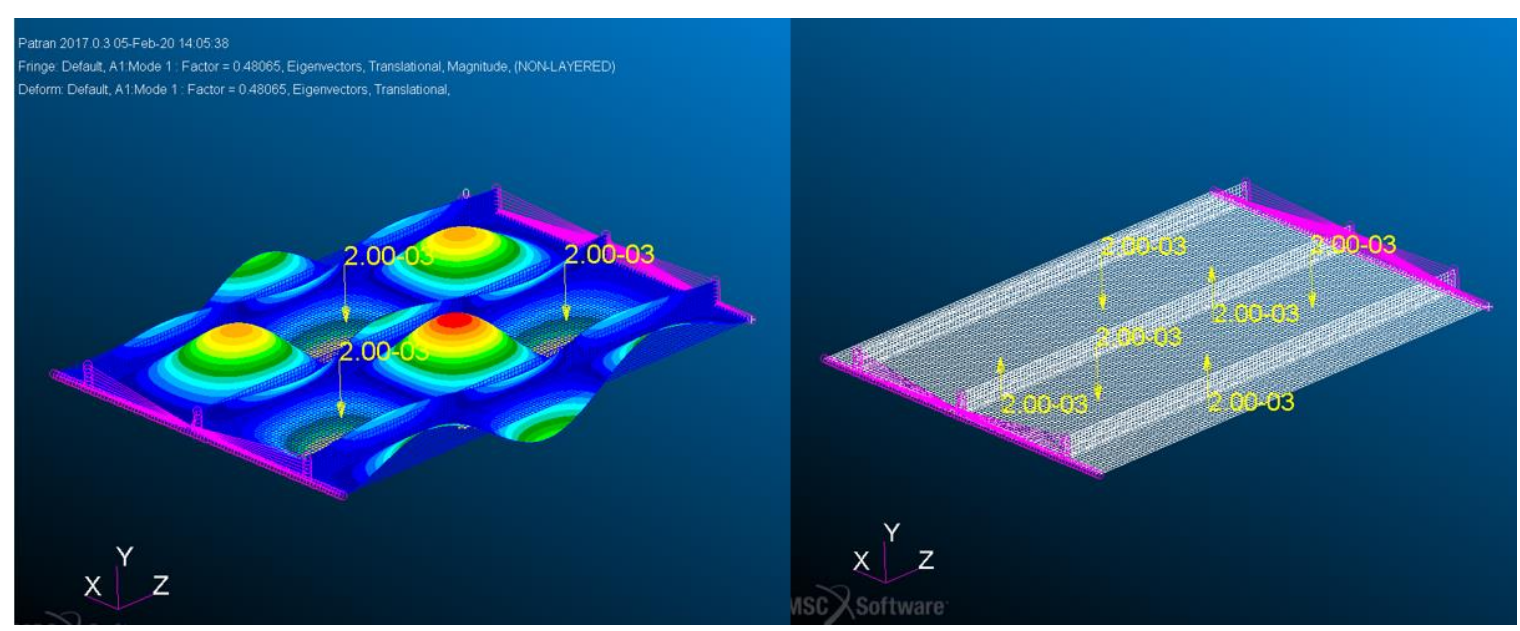

Şekil 7. Sonlu Elemanlar Modeline Girilen Yüklemeler

Panel burkulma çökme yüklemesini belirlemek için MSc Nastran SOL600 kullanılarak doğrusal olmayan analiz yapılarak sonuç kuvvet-yer değiştirme eğrisi olarak çizdirilir. Bu eğrinin kuvvet bölümündeki en yüksek değer, panelin çökme yüküne karşılık gelmektedir. Görüldüğü gibi bu değerden sonra panelin yük taşıma kapasitesi hızla düşmektedir. Grafikten bu değer 220,3 kN olarak belirlenmiştir. 


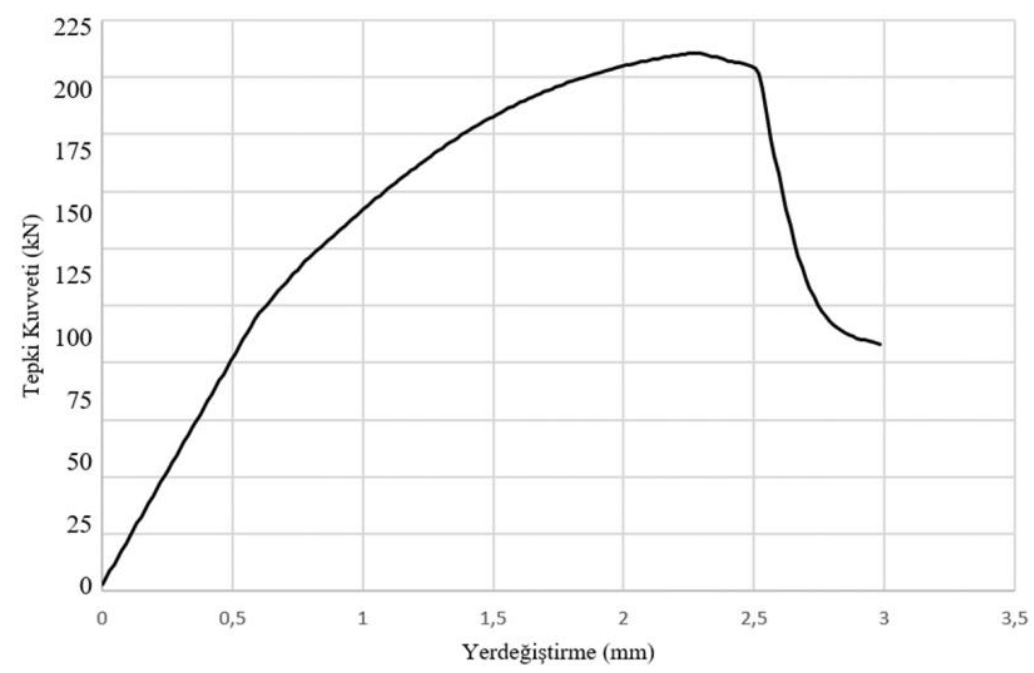

Şekil 8. Nonlinear Analiz için Kuvvet-Yer Değiştirme Grafiği

$$
\% \text { Hata }=\frac{216,6-220,3}{216,6} * 100=\% 1,7
$$

Yapılan sonlu elemanlar modeli sonucunda Tablo 4’te özetlendiği gibi \%1,6 ve \%1,7 hata oranları ile test sonuçları yakalanmıştır. Bu sonuçlar yapılan doğrusal ve doğrusal olmayan analizler için ayrı ayrı kabul edilebilir mertebelerdedir. Referans alınan makalede de benzer şekilde test sonuçlarına $\% 1.9$ ve $\% 12,6$ lık hata oranları ile yaklaşılmıştır.

Tablo 4. Test ve Sonlu Elemanlaro Sonuçları Karşılaştırma Tablosu.

\begin{tabular}{|l|l|l|}
\hline & İlk Burkulma Yükü (kN) & Nihai panel çökme yükü (kN) \\
\hline Numune_A Test Sonuçları & $74,5[1]$ & $216,6[1]$ \\
\hline Numune_A Fem Sonuçları & 75,7 & 220,3 \\
\hline \%Hata & 1,6 & 1,7 \\
\hline
\end{tabular}

FEM ve test sonuçları arasındaki farklar kabul edilebilir seviyededir. Bir sonraki kısımda aynı modelleme metodu kullanılarak paneller analiz edilip değerlendirilecektir.

\section{Araştırma Sonuçları ve Tartışma}

\subsection{Bulgular ve Tartışma}

Dört panel için yapılan sonlu elemanlar analizleri sonucu Bölüm II'de anlatılan sınır koşulları için

Tablo 5'de gösterilmiştir. I kesit alanlı panel için burkulma yükü $180 \mathrm{kN}$ olup aynı ağırlıkta, ana güçlendirici elemanlar arasına atılan yardımcı güçlendirici elemanlarla burkulma yükü $222.7 \mathrm{kN}$ a yükselmiştir. T kesin alanlı güçlendirici içeren paneller için de sonuç benzer olmaktadır. Aralara yardımcı güçlendirici elemanların eklendiği durumda panel burkulma yükü 172.6 kN dan $202.9 \mathrm{kN}$ a yükselmektedir.

I kesit alanlı panelde aralara eklenen yardımcı güçlendiriciler burkulma yükünün yanında panel çökme yükünü de artırmıştır. Ancak T kesit alanlı panelde araya eklenen yardımcı elemanlara rağmen panel çökme yükü 331.4 kN dan 295.3 kN a düşmektedir.

T kesit alanına sahip güçlendiriciler aynı ağırlık sağlanması için kalınlıkları azaltılarak üst kısımlarına malzeme eklenerek oluşturulmuşlardır. Bu kalınlık azalışı güçlendirici elemanları paneli destekleme açısından zayıflatmaktadır. Bu da Panel_C nin Panel_A dan daha düşük burkulma yüküne dayanmasının nedenidir. Ancak T kesit alanı I kesit alanına göre kendi içlerinde farklı sınır koşullarına sahiptir. I kesit alanın üst kısmı boş uç davranışı sergilerken, T için uç kısma eklenen malzeme bu güçlendirici elemanın sınır koşulunu değiştirerek panel çökme yükünde meydana gelen $220.8 \mathrm{kN}$ dan 331.4 e büyük artışına sebep olmuştur.

Tablo 5. Panellerin Burkulma ve Çökme Yükleri

\begin{tabular}{|l|l|l|l|l|}
\hline & Burkulma Yükü (kN) & Panel Çökme Yükü (kN) & \%BY Farkı & \%PÇY Farkı \\
\hline Panel_A & 180 & 220,8 & $0 \%$ & $0 \%$ \\
\hline Panel_B & 222,7 & 237 & $+23,7$ & $+7,3$ \\
\hline Panel_C & 172,6 & 331,4 & $-4,1$ & $+50,1$ \\
\hline Panel_D & 202,9 & 295,3 & $+12,7$ & $+33,7$ \\
\hline
\end{tabular}


Araya eklenen yardımcı güçlendirici elemanların her iki kesit alanlı konfigürasyon için de burkulma yükünü artırdığı gözlenmiştir.

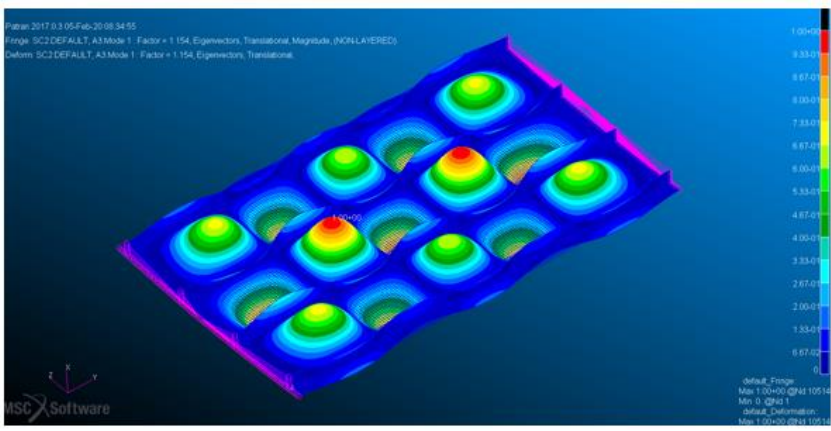

Panel_A

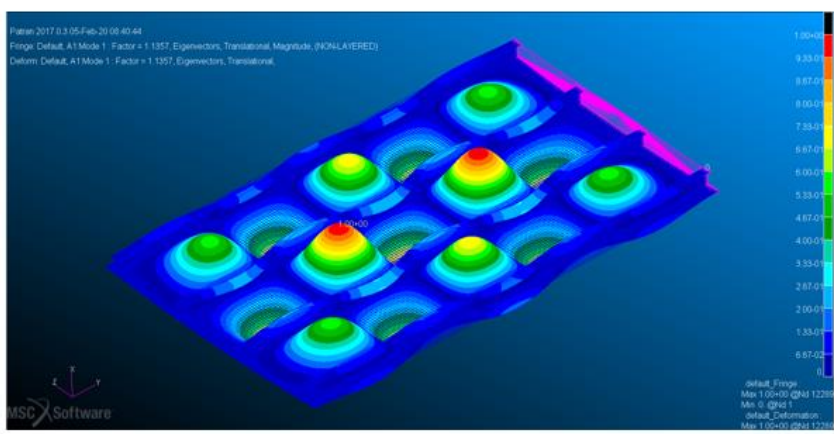

Panel_C

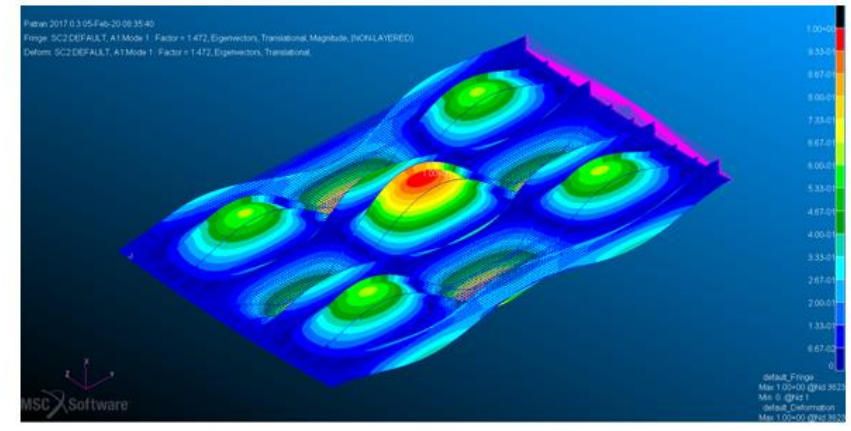

Panel_B

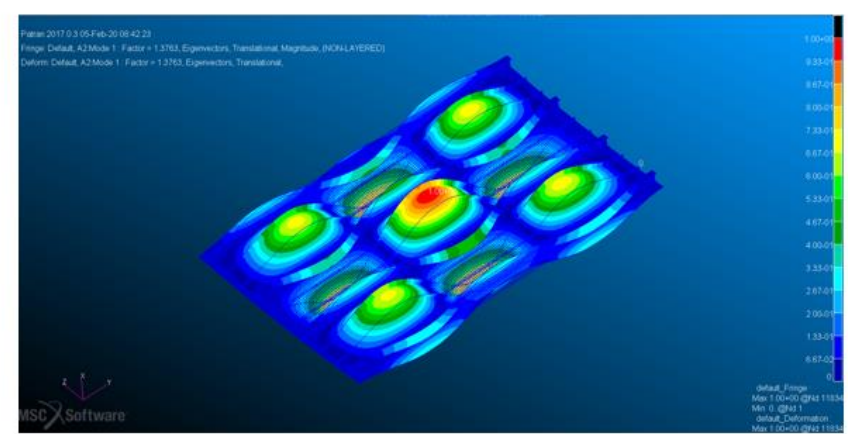

Panel_D

Şekil 9. Dört Panelin İlk Burkulma Sonlu Elemanlar Model Sonuçları

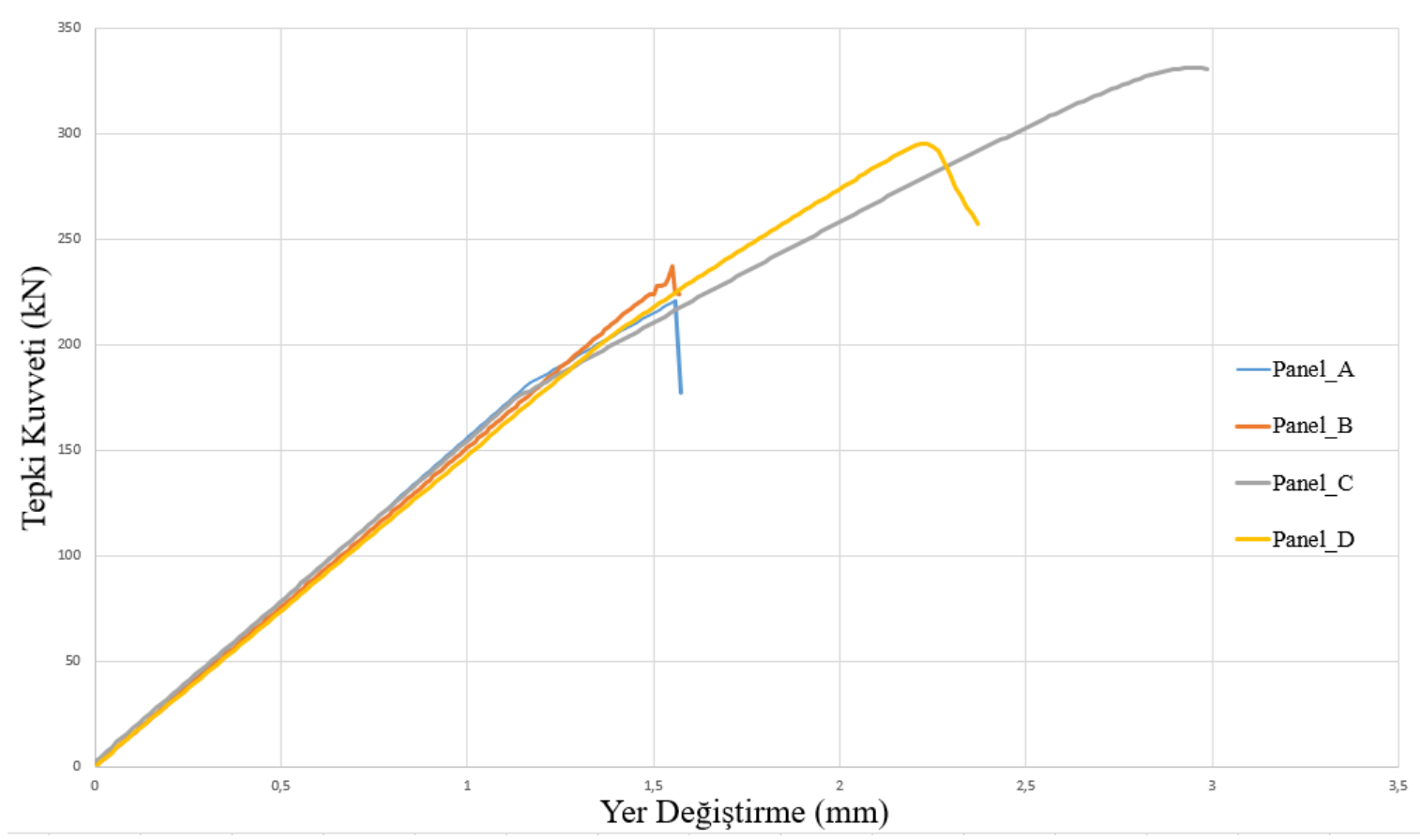

Şekil 10. Panellerin Nonlinear Analiz için Kuvvet-Yer Değiştirme Grafiği

Basma yüklemesine maruz kalan panellerin farklı tasarım seçenekleri bulunmaktadır. Bazı tasarımlar panellerin burkulmasına izin verip boyutlandırmayı panel çökme yüküne göre yapmaktayken bazı tasarımlar panellerin burkulmasına izin vermeyip boyutlandırma için bu yük değerini kullanmaktadır. Elde edilen bulgular sonucu tasarım kriterlerine göre farklı panel seçilmesi sonucu çıkmaktadır. Kriter olarak panel burkulma yükü dikkate alınacak tasarımlar için ana güçlendirici elemanların arasına eklenen yardımcı güçlendirici elemanlar burkulma yüklemesini \%23,7 ye kadar arttırdığı için tercih edilebilir. Panellerin burkulmasına izin verilen ve panel çökme yüklemesi için yapılan tasarımlar için ana güçlendirici elemanlar daha önemli paya sahip olup T kesit alanlı güçlendirici kullanmak yük taşıma kapasitesini $\% 50.1$ oranında artırmaktadır. 


\section{Sonuç}

Ana güçlendirici elemanlar arasına yardımcı güçlendirici elemanlar eklemek panel burkulma performansını sırasıyla I ve T kesin alanlı ana güçlendirici eleman kesit alanlı paneller için \%23,7 ve \%17.6 artırmaktadır.

Panel çökme yükü için daha önemli paya sahip olan tasarım parametresi ana güçlendirici eleman kesit alanıdır. T kesit alanına sahip güçlendirici eleman kullanmak aynı ağırlıkta panel için I kesit alanlı panele göre \%50.1 daha fazla yük taşıyabilmektedir.

Yardımcı güçlendirici elemanlar burkulma yükünü artırdığı için panel burkulması ve çökme yükü arasında daha az fark olmaktadır. Panel tasarımlarında bu elemanları eklemek, tasarım kriteri olarak panel burkulması seçilmiş durumlarda daha hafif tasarımlara imkân verecektir.

\section{Kaynakça}

[1] D.Quinn, A. Murphy, W. McEwan, F. Lemaitre, "Stiffened panel stability behaviour and performance gains with plate prismatic sub-stiffening", Thin-Walled Structures, July 2009

[2] J. Munroe, K. Wilkins, and M. Gruber, “ Integral Airframe Structures (IAS)-Validated Feasibility Study of Integrally Stiffened Metallic Fuselage Panels for Reducing Manufacturign Costs”,s. 29, 2000

[3] A. Murphy, D. Quinn, P. Mawhinney,M. Özakça, Van Der Ven S., "Tailoring Static Strength Performance of Metallic Stiffened Panels by Selective Local Sub-Stiffening", 47 th AIAA/ASME/ASCE/ASH/ASC Structures, Structural Dynamics, and Materials Confere, 2006

[4] Bushnell D, Rankin C.," Optimum design of stiffened panels with sub-stiffeners." In: Proceedings of the forty sixth AIAA/ASME/ASCE/AHS/ASC structures, structural dynamics \& materials conference. Austin, Texas: 18-21 April 2005, AIAA 2005-1932.

[5] Watson A, Featherston CA, Kennedy D. "Optimization of post-buckled stiffened panels with multiple stiffener sizes." In: Proceedings of the forty eighth AIAA/ ASME/ASCE/AHS/ASC structures, structural dynamics, and materials confer- ence. Honolulu, Hawaii: 23-26 April 2007, AIAA 2007-2207.

[6] MMPDS-11: Metallic Materials properties Development and Standardization. Federal Aviation Administiration; Battelle Memorial Institute [distributor],2016.

[7] K. L. Tran, Cyril Douthe, Karam Sab, J. Dallot, L. Davaine. "Buckling of stiffened curved panels under uniform axial compression.” Journal of Constructional Steel Research, Elsevier, 2014, 103, pp 140-147.

[8] W. Ramberg, W. R. Osgood, "Description of Stree-Strain Curves by Three Parameters", National Advisory Committe for Aeronautics, 1943 